\title{
SEGMENTAL FRACTURE OF PROXIMAL SHAFT FEMUR OF POLIO AFFECTED PARALYTIC LIMB TREATED WITH 95 DEGREE ANGLED PLATE FIXATION BY MIPO TECHNIQUE
}

Rajan Sarad1', Rajan Sharma², Raj Kumar Aggarwal ${ }^{3}$

\section{HOW TO CITE THIS ARTICLE:}

Rajan Sarad, Rajan Sharma, Raj Kumar Aggarwal. "Segmental Fracture of Proximal Shaft Femur of Polio Affected Paralytic Limb Treated with 95 Degree Angled Plate Fixation by MIPO Technique". Journal of Evolution of Medical and Dental Sciences 2014; Vol. 3, Issue 61, November 13; Page: 13628-13631,

DOI: $10.14260 /$ jemds/2014/3820

ABSTRACT: Subtrochanteric fractures extending below lesser trochanter are always difficult to treat and their higher incidence of unsatisfactory results are noted after operative treatment. There are various implants available for fixation but in this study we did 95 DEG ANGLED PLATE FIXATION BY MIPO TECHNIQUE

KEYWORDS: Segmental fracture, paralytic limb, MIPO technique.

INTRODUCTION: In subtrochanteric fractures restoration of femoral length and rotation and correction of femoral head and neck angulation to restore adequate abductor tension and strength are essential to restoring maximal ambulatory capacity. ${ }^{1}$

CASE REPORT: 40 YEAR OLD MALE PRESENTED WITH H/O OF HIGH ENERGY TRAUMA WITH POLIO AFFECTED PARALYTIC LIMB.

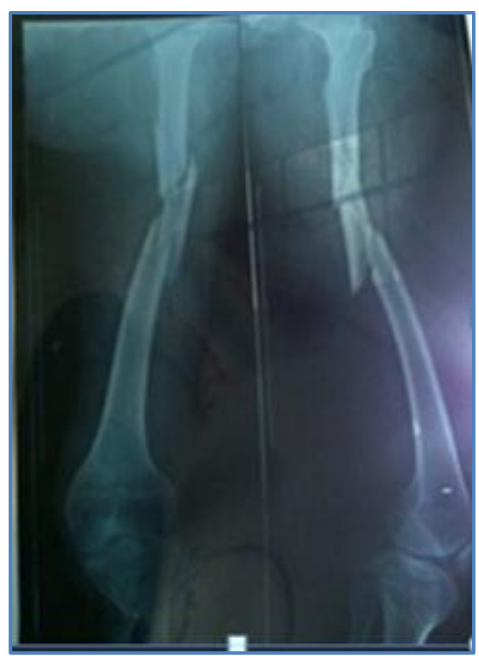

PRE OPERATIVE XRAY SHOWING SEGMENTAL FRACTURE OF PROXIMAL SHAFT RT FEMUR WITH 8MM MEDULLARY CANAL

\section{Options available for Fixation:}

- Recon nail.

- Intramedullary nail.

- Proximal femur locking plate.

- 95 degree angle blade plate by mipo. 


\section{CASE REPORT}

PROCEDURE: Fracture is segmental involving lesser trochanter with 8mm narrow medullary canal intramedullary nailing is not possible, ${ }^{2}$ so we preferred 95 DEG ANGLED PLATE FIXATION BY MIPO TECHNIQUE.
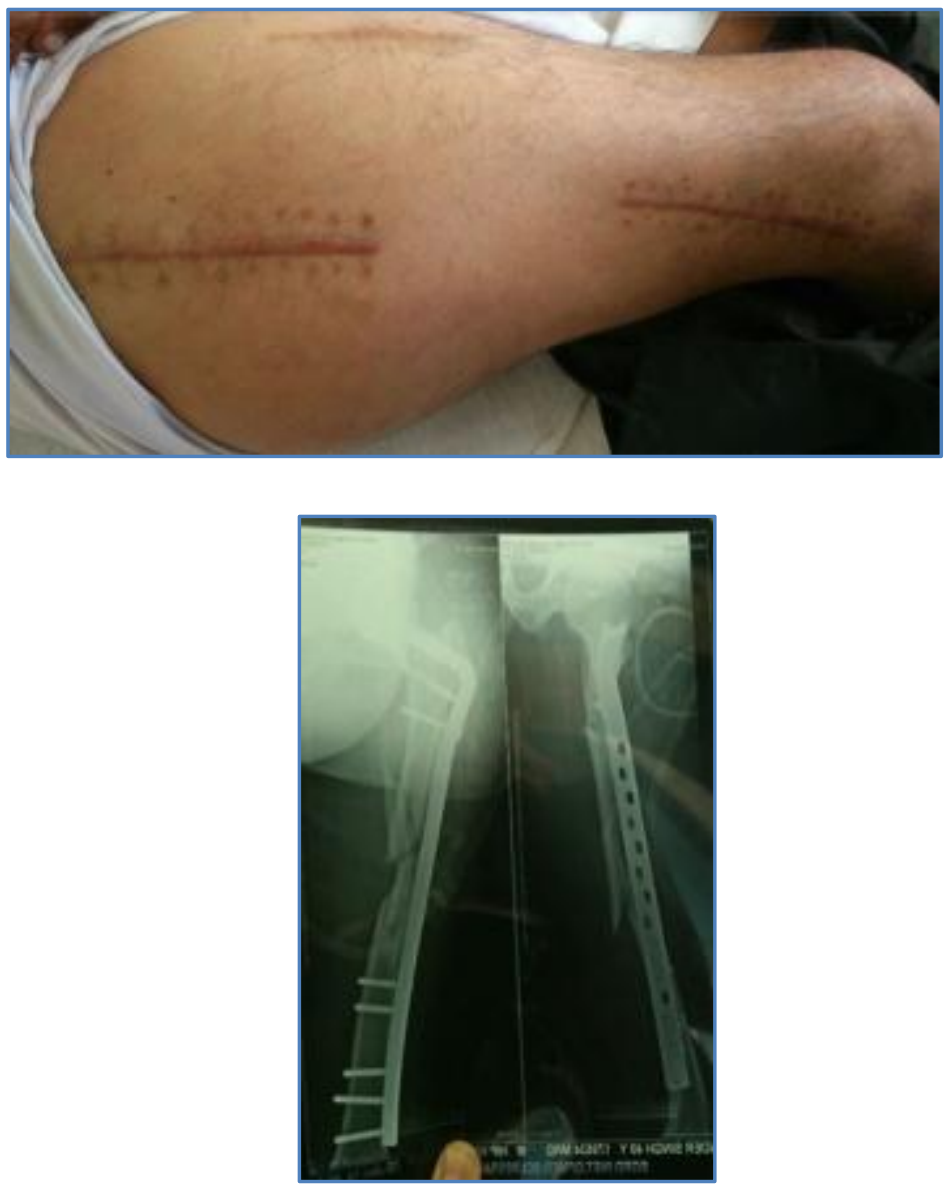

Post OP X-ray

\section{Advantages of Angle Blade Plate Fixation by Mipo Technique3:}

- It is very strong implant.

- Blade of the plate gives very strong fixation.

- No fracture hematoma disturbance and biological fixation due to mipo technique. ${ }^{4}$

- Can be put in those patients whose fracture line extends upto greater trochanter, where recon nail fixation is not possible.

- Can be put in patients with narrow medullary canal.

CONCLUSION: There are many techniques available but none provide good fixation and stability, 95 degree angle blade plate by mipo technique is next best option of high energy trochanteric subtrochanteric fractures that are unfit for nailing because of narrow medullary canal or fracture involving entry point.5, 6 


\section{RESULTS:}

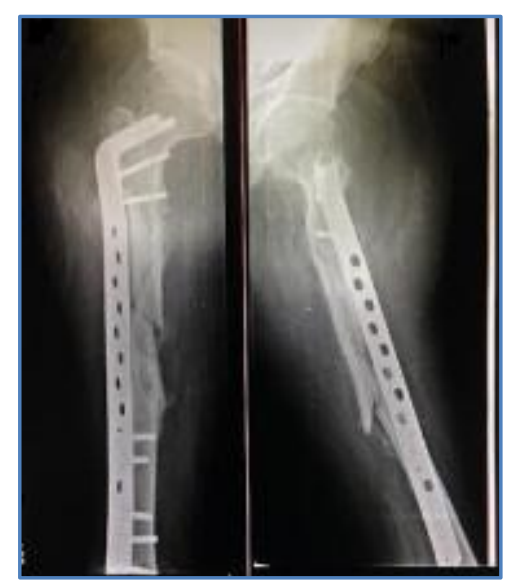

Post Op x-ray after 2 months showing good sign of union without any complication

\section{REFERENCES:}

1. Schatzker J and Tile M. The Rationale of Operative Fracture Care. Berlin: Springer Verlag, 1987.

2. Bolden C, Seibert FJ, Fankhauser F, Peicha G, Greichnig W, Szyszkowitz R. The proximal femoral

3. Nail (PFN)-a minimally invasive treatment of unstable proximal femoral fractures; a prospective Study of 55 cases with follow -up of 15 months. Acta Orthopedic Scand 2003; 74:53-8.

4. Raiturker PPP; Salunkhe AA. Minimally invasive plate osteoynthesis (MIPO) in the treatment of multifragmentary fractures of the femur. Bombay Hospital Journal. 2001 Jan; 43(1): 162-8.

5. Muller ME, Allgower M, Schneider R et al. Manual of Internal Fixation, 3rd Ed. Berlin: Springer Verlag, 1990.

6. Kinast C, Bolhofner BR, Mast JW and Ganz R. Subtrochanteric fractures of the femur: results of treatment with the 95" condylar blade plate. Clin Orthop 1989; 238: 122. 


\section{CASE REPORT}

\section{AUTHORS:}

1. Rajan Sarad

2. Rajan Sharma

3. Raj Kumar Aggarwal

\section{PARTICULARS OF CONTRIBUTORS:}

1. Assistant Professor, Department of Orthopaedics, Sri Guru Das Institute of Medical Sciences, Vallah Amritsar, Punjab.

2. Assistant Professor, Department of Orthopaedics, Sri Guru Das Institute of Medical Sciences, Vallah Amritsar, Punjab.

3. Professor, Department of Orthopaedics, Sri Guru Das Institute of Medical Sciences, Vallah Amritsar, Punjab.

\section{NAME ADDRESS EMAIL ID OF THE} CORRESPONDING AUTHOR:

Dr. Rajan Sharma, 184, Medical Enclave, Amritsar-143001, Punjab.

Email: sharmarajan29@yahoo.com

Date of Submission: 21/06/2014.

Date of Peer Review: 23/06/2014.

Date of Acceptance: 03/07/2014.

Date of Publishing: 13/11/2014. 